$\mathbb{T}$ periodica polytechnica

Civil Engineering

$57 / 1(2013) 83,95$

doi: $10.3311 /$ PPci.2144

http://periodicapolytechnica.org/ci

Creative Commons Attribution (i)

RESEARCH ARTICLE

\section{Validation of an analytical model for curved and tapered cellular beams at normal and fire conditions}

\author{
Sebastien Durif / AbdelHamid Bouchaïr / Olivier Vassart
}

Received 2012-10-08, accepted 2012-12-17

\begin{abstract}
The growing use of cellular beams in steel construction leads to the development of various configurations such as curved and tapered cellular beams. In order to provide a tool predicting the behavior of those beams for design applications, the CTICM developed a software based on analytical formulas with adaptation to the curved and tapered cellular beams. Recently, the analytical formulas were adapted to fire conditions. In this paper, a nonlinear numerical model is developed and performed to validate the analytical approach. The model is applied to curved and tapered beams considering various opening and support configurations in normal and fire conditions. The comparison between the numerical and the analytical results validates and shows the possibilities of the analytical model and its limits.
\end{abstract}

\section{Keywords}

Cellular beams $\cdot$ curved beams $\cdot$ tapered beams $\cdot$ analytical model $\cdot$ Iso-fire $\cdot$ finite element model

\section{Sebastien Durif}

Clermont Université, Université Blaise Pascal, Institut Pascal, BP 10448, F63000 Clermont-Ferrand

CNRS, UMR 6602, Institut Pascal, F-63171 Aubière, France e-mail: sebastien.durif@univ-bpclermont.fr

\section{AbdelHamid Bouchaïr}

Clermont Université, Université Blaise Pascal, Institut Pascal, BP 10448, F63000 Clermont-Ferrand

CNRS, UMR 6602, Institut Pascal, F-63171 Aubière, France e-mail: Abdelhamid.bouchair@univ-bpclermont.fr

\section{Olivier Vassart}

ArcelorMittal Belval\&Differdange S.A., Research Centre, Esch/Alzette, G.-D, Luxembourg

e-mail: olivier.vassart@arcelormittal.com

\section{Introduction}

The use of cellular beams, with regularly spaced circular openings, increases in steel construction. The openings allow passing, through the web of the beam, conducts and services which reduces the floor depth. Those beams are made from hot rolled profiles and provide, for an equivalent weight of steel, higher mechanical performances compared to the parent standard profile. The Fig. 1 1 illustrates the design process of a cellular beam [1]. Nowadays cellular beams can be considered as the most popular long span system.

Kerdal and Nethercot [2] were the first authors who have described the 6 main failure modes of castellated beams, which are beams with uniformly distributed hexagonal openings. The failure modes can be of two categories: global and local. The global failure modes are similar to those of full web beams such as the lateral torsional buckling, the global shear failure or the bending failure. The local failure modes are specific to the beams with web openings. Three local failures can be observed: the Vierendeel yielding, the web-post buckling and the web-post welding fracture.
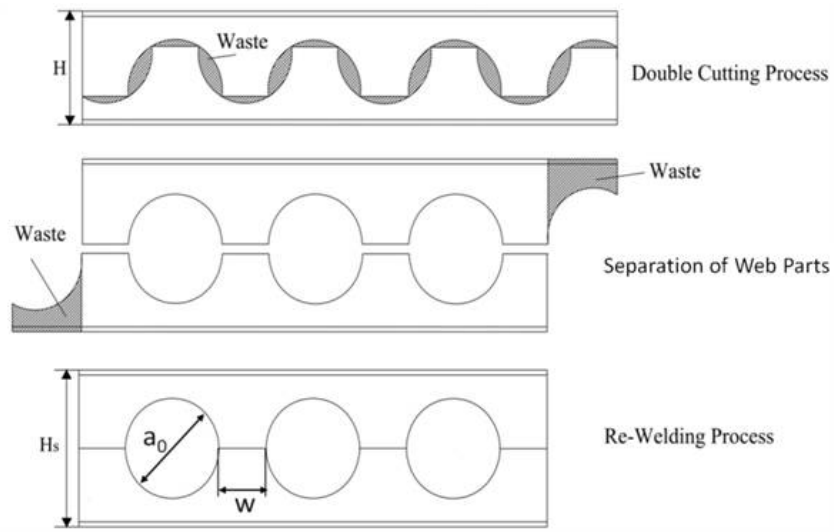

Fig. 1. Fabrication process of cellular beam

The experimental and numerical researches led on cellular beams revealed that their failure modes are similar to those observed on castellated beams [3-5]. However, changing the opening shape from hexagonal to circular shape affects the local behavior of the opening. As a consequence, the existing analytical 
methods developed for castellated beams were adapted to cellular beams [6-8]. These developments are based on experimental and numerical studies performed in order to understand the behavior of the cellular beams and to propose analytical methods predicting their ultimate resistances. The main studies are summarized hereafter.

In general, to analyze the local behavior of beams with openings, the beam lateral torsional buckling is prevented using sufficient lateral supports. Thus, the main failure modes due to the existence of large circular openings are the Vierendeel yielding and the web-post buckling. Those failure modes are illustrated on Fig. 2 for the case of composite cellular beams.

The evolution of the fabrication technology and the aesthetical and mechanical performances implied the extension of the fields of application of these beams. Nowadays, the cellular beams can be designed using a variation of heights (tapered beams) or a curvature (curved beams). For tapered cellular beam, the fabrication uses an inclined oxy-cutting line in comparison with the straight beam. In the case of curved cellular beam, the two members of the cellular beam are curved separately before re-welding. Thus, it is necessary to well estimate the curvature to be realized, in order to obtain circular openings in the final curved cellular beam.

The main analytical studies performed on cellular beams led to a common approach defining the Vierendeel yielding strength [3, 4, 9, 11]. This failure mode is relatively common and the analytical methods proposed by all the authors are similar. However, for the web-post buckling, the analytical methods proposed by the authors are different. Lawson [4] introduced a simplified method to predict the web-post buckling resistance, based on an effective length of the compression field in the intermediate web-post, modeled as a strut. This method has been introduced in the design guide published by RFCS [8]. However, this method shows conservative results in comparison with finite element model results according to Wong et al. [12]. The CTICM proposed a new analytical model to predict the webpost buckling failure mode [11]. The model is calibrated against the results of more than 100 numerical simulations [11] and has been recently extended to fire conditions [13].

Fire can often be destructive for structures [14], especially for slender structures such as cellular beams. Many research works have been done to define the ultimate resistance of cellular beams in fire conditions [15-17]. The authors agree with the fact that the actual design rules for fire protection of cellular beams have to be improved. Indeed, one main rule, initially proposed by the BS 5950 and still used in steel construction, proposes a supplementary fire protection thickness of $20 \%$ in comparison with the full web beam. This approach is conservative and leads to high costs of fire protection for cellular beams [13].

The existing experimental and numerical studies, in fire conditions, show that the main failure mode for cellular beams is the web-post buckling due to the important loss of stiffness of steel at high temperatures [12, 16, 17]. Thus, the prediction of the fire resistance of cellular beams, represented by the critical temperature, depends mainly on the web-post buckling resistance under high temperatures. The analytical method developed by the CTICM, adapted to fire conditions, allow defining the critical temperature for the web-post buckling of straight cellular beams. These analytical methods developed for straight cellular beams have been extended to tapered and curved beams and then implemented in the software $\mathrm{ACB}+$. The analytical model has been validated in normal conditions [11] and in fire conditions for straight beams [13].

The main principles of the analytical method in normal and fire conditions, corresponding to the Vierendeel mechanism and the web-post buckling failure modes, are presented briefly hereafter. An extension of these analytical models is done to cover the curved and tapered beams, in normal and fire conditions. This extension of the analytical models is validated by comparison of their results with those given by the nonlinear finite element model developed using the software SAFIR.

The finite element model developed in the present study uses shell elements for non-linear calculations in order to predict accurately the plastic behavior and the local buckling of cellular beams. The FEM model is taken as a reference to evaluate the accuracy of the analytical method in both normal and fire conditions. Three configurations are studied, bi-supported curved beam, bi-supported tapered beam and cantilever tapered beam, which are common configurations for cellular beams in steel construction and available in the analytical software. The comparisons, between both numerical and analytical models, concern failure modes and the failure loads for normal conditions or the critical temperatures for fire conditions.

\section{Mechanical behavior of cellular beams: analytical ap- proach}

The analytical approaches predicting the resistance of cellular beams are based on the comparison between the internal forces around each opening and the local resistances. The internal forces are obtained from the global bending moment, shear force and axial force. Two main local failure modes are considered: the Vierendeel mechanism and the web-post buckling. The analytical methods, presented hereafter, are generally used for straight cellular beams. They are adapted to cover the case of curved or tapered beams. The case of fire resistance is taken into account considering the elevation of temperature and its effect on the mechanical characteristics of materials.

\subsection{Internal forces in a cellular beam}

As cellular beam is composed of regularly spaced circular openings, its behavior is assimilated to that of a Vierendeel beam (Fig. 3). The main assumption simplifying the analysis is to consider internal hinges at the mid-span of each member (Fig. 3 . This simplification can be justified by the fact that, in a Vieerendeel beam loaded at the nodes of the upper members, the bend- 


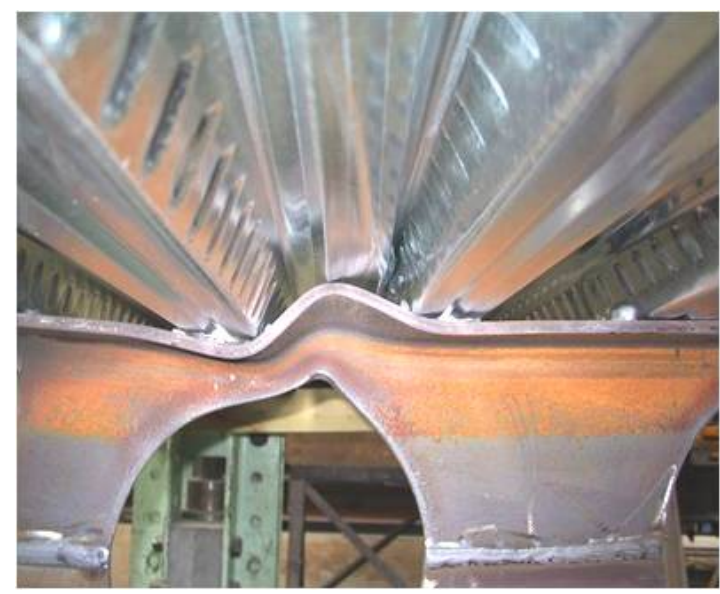

a) Vierendeel mechanism

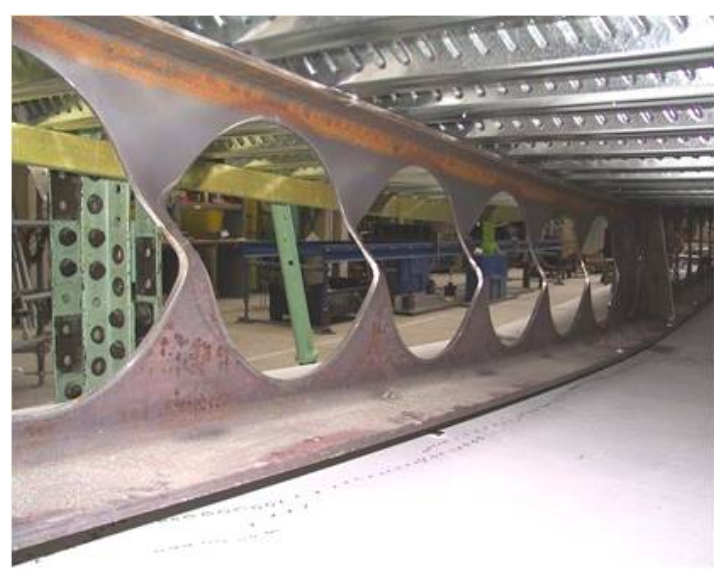

b) Web-post buckling mode

Fig. 2. Failure modes of composite cellular beams

ing moment diagrams in each member are bi-triangular. For the most loaded members, the point of zero bending moment is at the mid-length (positions of the hinges in Fig. 3). The positions of the internal hinges simplify the analytical calculation of the internal forces in the beam. In each hinge, the unknown forces are the normal force $N_{T}$ and the shear force $V_{E d}$ (Fig. 4). These internal forces are obtained from the external applied loads using Equations (1) and (2). The internal forces considered around a circular opening are illustrated on Fig. 4

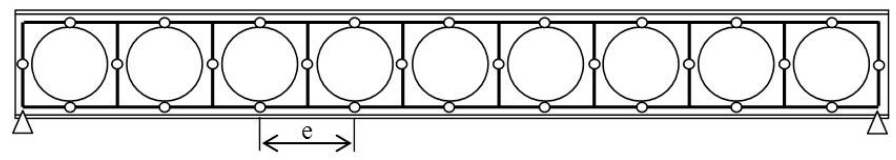

Fig. 3. Equivalence between a cellular beam and a Vierendeel beam

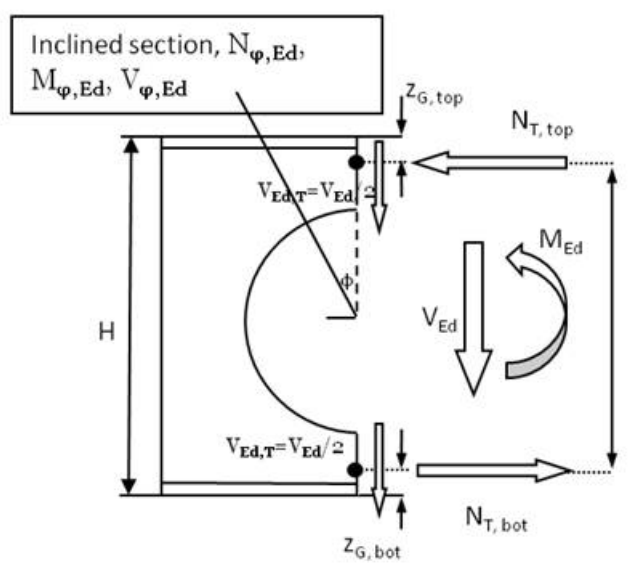

Fig. 4. Local force distribution around a circular opening [19]

The internal forces $N_{T, t o p}, N_{T, b o t}$ and $V_{E d, T}$ of the upper and lower members are calculated from the global bending moment $\left(M_{E d}\right)$ and shear force $\left(V_{E d}\right)$ at the mid-length of the opening considered using the Equations (1) and (2).

$$
\begin{aligned}
& N_{T, \text { top }}=N_{T, \text { bot }}=M_{E d} / d_{G} \\
& V_{T, \text { top }}=V_{T, \text { bot }}=V_{E d} / 2
\end{aligned}
$$

\subsection{Vierendeel mechanism}

The local failure mode in bending, called Vierendeel mechanism, has been observed by Altifillish in 1957 [20].The transfer of global shear force $\left(V_{E d}\right)$ is equilibrated by the formation of local plastic hinges around the opening due to this local bending. To check the resistance of opening, regarding this local bending, the analytical method is based on the calculation of the internal forces and the resistance of all the inclined Tee sections around the opening (Fig. 4) [11]. The internal forces $\left(N_{T}, V_{T}\right)$ in the mid-length of the opening are defined from the global bending and shear. They are used to calculate the internal forces in each inclined Tee section defined by the angle $\varphi$ (Fig. 4) according to the Equations (3) to (5) given for the top-left quarter of the opening. The resistance of each inclined Tee sections is based on the existing approaches considering the classification of opening with either plastic or elastic section resistance [4, 8, 21].

$$
\begin{aligned}
N_{\varphi, E d} & =N_{T, \text { top }} \times \cos \frac{\varphi}{2}+V_{T, \text { top }} \times \sin \frac{\varphi}{2} \\
V_{\varphi, E d} & =N_{T, \text { top }} \times \sin \frac{\varphi}{2}-V_{T, \text { top }} \times \cos \frac{\varphi}{2} \\
M_{\varphi, E d} & =V_{T, \text { top }} \times u-N_{T, \text { top }} \times v
\end{aligned}
$$

\subsection{Web-post buckling}

The web-post buckling is a local instability observed experimentally [20] by Sherbourne in 1966, Halleux in 1967 and Bazile and Texier in 1968. This instability is characterized by an out of plane displacement of the web-post with double curvature (Fig. 5).

The difference of axial forces between two openings is equilibrated in the web-post by the horizontal shear force $V_{h, E d}$ (Equation (6)) and the moment $M_{h, E d}$ (Equation 7). This moment is equal to zero when the openings are centered. Those internal forces generate a local bending moment in the web-post $M_{c, E d}$ (Equation (8)). The compressive stress $\sigma_{w E d}$ due to this local 


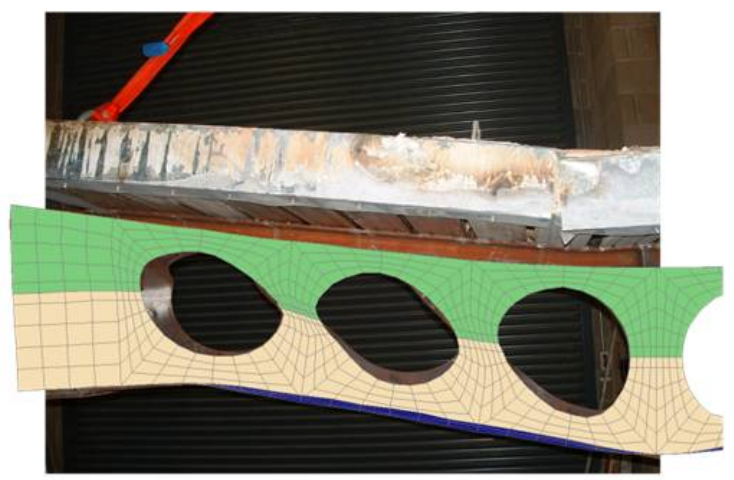

Fig. 5. Finite element model (SAFIR) of web-post buckling and experimental observation [13]

bending moment initiates the local buckling.

$$
\begin{aligned}
V_{h, E d} & =N_{t o p, i+1}-N_{t o p, i} \\
M_{h, E d} & =\left(V_{b o t, i+1}+V_{b o t, i}\right) \times \frac{e}{2}-V_{h} \times d_{l o w} \\
M_{c, E d} & =V_{h, E d} \times y-M_{h, E d}
\end{aligned}
$$

As the width of the sections increases with the increase of the internal moment $\left(M_{c, E d}\right)$, it is necessary to determine the position ( $\mathrm{dw}$ ) of the critical section. This section corresponds to the maximum compressive stress (see Fig. 6). The Fig. 6 shows the "X modulus" used to present the distribution of internal loads in both sides of an intermediate web-post. This model allows describing the internal loads used for the verification of the webpost buckling resistance.

The critical section position (dw) depends on the geometrical characteristics of the opening [13,22]. The maximum compressive stress at this section is calculated on the free edge of the opening and compared to the buckling stress resistance to check the resistance of the section according to Equations (9) and (10).

$$
\begin{aligned}
& \sigma_{w E d} \leq \kappa \sigma_{w R d} \\
& \sigma_{w, E d}=6 M_{c, E d} / l_{w}^{2} t_{w}\left(1-4\left(d_{w} / a_{0}\right)^{2}\right)
\end{aligned}
$$

$\sigma_{w R d}$ is the principal stress resistance. Its calculation is based on the approach of EC3-1-1. However, to take into account the specificity of the opening, the factor $k$ of post-critical resistance is calibrated on the basis of numerical simulations [11]. The curve "a" of EN1993-1-1 is used to calculate the reduction factor $\chi$ in Equation (11). This curve has been chosen after calibration with numerical and experimental results [11].

$$
\sigma_{w, R d}=\frac{\chi \xi f_{y}}{\gamma_{M 1}}
$$

The parameters of the Equation (11) are given in the Equations 12 to 15 .

$$
\begin{aligned}
& \chi=\frac{1}{\Phi+\left[\Phi^{2}+\bar{\lambda}^{2}\right]^{0.5}} \text { and } \chi \leq 1 \\
& \Phi=0.5 \times\left[1+0.21 \times(\bar{\lambda}-0.2)+\bar{\lambda}^{2}\right] \\
& \bar{\lambda}=\sqrt{\frac{\xi f_{y w}}{\sigma_{w C r}}}
\end{aligned}
$$

Where $\sigma_{w C r}$ is the critical stress for the out of plane buckling of the intermediate web-post, and the coefficient $\xi$ depends on the shape of the opening. Those two parameters are calibrated against finite element calculations [11]. Finally the verification given in Equation (9) is used to check the buckling strength of the intermediate web-post. Details on the calculation are given in the references [11,22]. The adaptation of this analytical model to the configurations of curved or tapered beams and to fire conditions is presented hereafter.

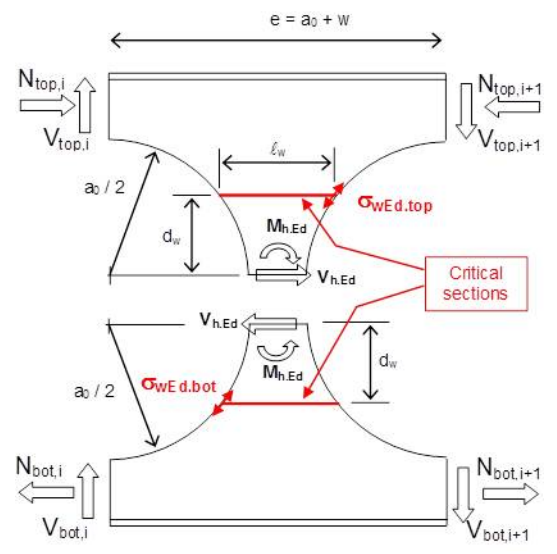

Fig. 6. Local forces and position of the critical sections in the intermediate web-post

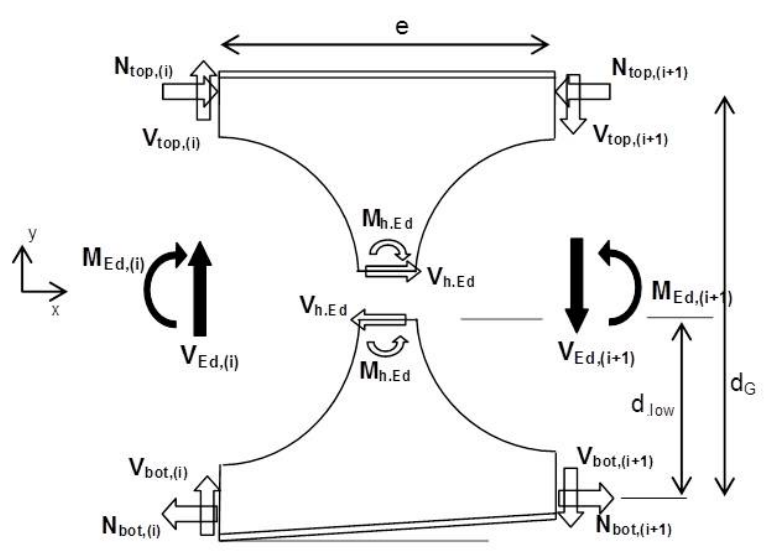

Fig. 7. "X modulus" for a tapered beam 23

\subsection{Tapered and curved cellular beams}

The tapered beams are characterized by the variation of the section heights along the beam. Thus, the internal loads are different from those of the straight beams. The difference is particularly non negligible for tapered beams with a single slope of the upper or the lower flange. In this case, with a vertical load, the inclination of the neutral axis with regard to the horizontal line creates a global axial force.

It has been decided to conserve the same approach used for straight beams. Thus, the Vierendeel principle can be used separating the beam in different " $X$ " elements as shown in Fig. 7 . The Fig. 7 presents the $\mathrm{X}$ modulus for a tapered beam with an inclined lower flange. 
Although the global forces change, the same model can be used for the calculation of the web-post-buckling. It can be assumed that the different internal loads are in the same configuration as for the straight beam and the Tee sections at the mid-span of the opening are considered vertically.

In the curved beam, the curvature creates an axial force in addition to the global bending moment and shear force. This global axial force influences the internal loads around the opening. Regarding the relatively small curvature to be used in the construction, the "X modulus" of curved beam is considered as straight one to simplify the calculations. Thus, the effect of the curvature is considered only to evaluate the global loads: bending moment, shear force and axial force. These loads are then distributed in the opening members with the same method as presented for straight beams. The Vierendeel moment and the compressive stresses for the web-post buckling are calculated according to the approach presented here before for straight beams.

The adaptation of the analytical method to fire conditions is presented in the next section. Indeed, the elevation of temperature changes the material characteristics, thus, it affects the buckling strength of the intermediate web-post and the plastic strength of the Tee sections around the opening.

\subsection{Fire conditions}

The analytical model used in normal conditions is extended to cover the fire conditions. Thus, to calculate the resistance of cellular beams under elevated temperatures, the evolutions of the material properties are considered using the reduction factors $k_{y, \theta}$ (elastic limit) and $k_{E, \theta}$ (Young modulus) of the EN1993-1-2 [21] (see Fig. 8).

It can be seen on the Fig. 8 that the elastic Young modulus decreases faster than the elastic limit. This can explain the numerous failures due to instability observed in case of elevated temperatures. In cellular beams, the web-post buckling is the predominant failure mode in fire.

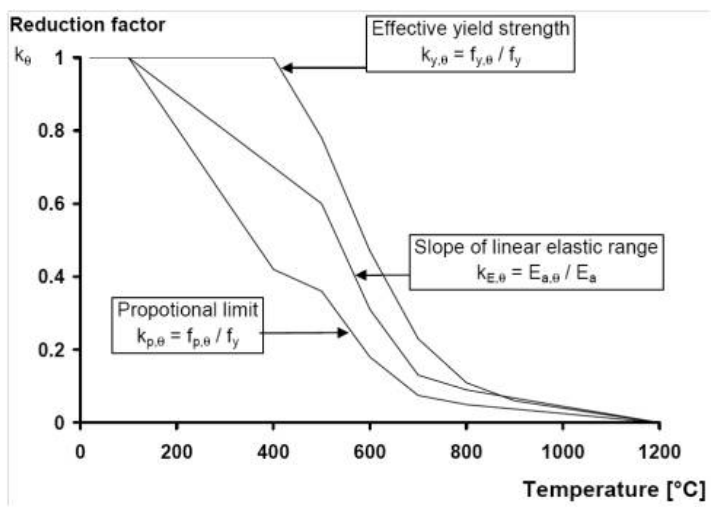

Fig. 8. Reduction factors for the stress-strain relationship of carbon steel at elevated temperature [21]

Even with the elevation of temperature, the verification of each inclined Tee section to the local Vierendeel bending is similar to that of normal conditions. However, the change is con- sidered through the decrease of the elastic limit according to the elevation of temperature and the possible change in the Tee sections classifications considering the reduction factor of 0.85 in the calculation of the coefficient $\varepsilon[21]\left(\varepsilon=0.85 \sqrt{235 / f_{y}}\right)$.

Furthermore, for the web-post buckling, the fire conditions modify the buckling curve that has to be considered in the analytical approach to calculate the principal stress resistance. The fire curve is chosen according to the factor $\alpha$ (Eq. (17)).

The web-post resistance is checked comparing the compressive stress (Eq. (3)) and the principal stress resistance defined by the Equation (4) based on the same approach as Eurocode 3-1-1 [11].

$$
\sigma_{w, f i, R d}=\frac{\chi_{f i} \cdot \xi \cdot k_{y, \theta} \cdot f_{y}}{\gamma_{M 1}}
$$

In this case, the coefficient $\chi_{f i}$ is defined by Equation (12) with:

$$
\begin{array}{r}
\Phi_{\theta}=\frac{1}{2}\left[1+\alpha \bar{\lambda}_{\theta}+\bar{\lambda}_{\theta}^{2}\right] \\
\alpha=0.65 \sqrt{\frac{235}{f_{y}}}
\end{array}
$$

In the Equation (15), the parameters $\sigma_{w, c r}$ and $\xi$ defined at normal conditions remain the same in fire conditions [13]. The adaptation of the analytical method to fire conditions for straight cellular beams has been validated on the basis of comparison with finite element model results for various geometric configurations [13]. In the present study, the extension of the analytical model to the cases of curved and tapered cellular beams is done for normal and fire conditions. The accuracy of the analytical model is checked using a nonlinear finite element model. All calculations made in fire conditions consider a time-temperature curve ISO 834 for the elevation of the gas temperature (Eq. (18)) in analytical and numerical calculations.

$$
\Theta_{g}=20+345 \log _{10}(8 t+1)
$$

Where [24]:

- $\Theta_{g}$ is the gas temperature in the fire compartment

- $t$ is the time

\section{Finite Element Model}

A finite elements model is developed using the software SAFIR, for tapered and cellular beams, and used as a basis to validate the results of the analytical model in normal and fire conditions. The model uses shell elements with four Gauss points in the surface and six integration points in the shell thickness. This model allows making nonlinear calculation, thus, it takes in account geometrical and material nonlinearities. The material used considers an elastic perfectly plastic law for steel. Furthermore, in the case of elevated temperatures, the evolution of the stress-strain curves are considered according to the parameters defined in the EN1993-1-2 [21].

The shell element is particularly efficient to represent local instability with limited resources [25]. Existing studies on cellular 
beams showed that the shell elements represent well the behavior of cellular beams including the local instabilities as the webpost buckling for closely spaced circular openings [19 26-28].

Various experimental studies have been led in order to validate the application of this finite element software representing the behavior of cellular beams at normal and fire conditions. First, Nadjai et al. validated the software through experimental tests on composite cellular beams in fire conditions [16]. Furthermore, the authors presented experimental tests on cellular beams with sinusoidal openings in normal conditions [23]. Both studies revealed the good capacity of the software to represent accurately the experimental behavior and validated the model. Therefore, this numerical tool is used to study the curved or tapered cellular beams in normal and fire conditions.

Three configurations of cellular beams are studied, bisupported curved beam, bi-supported tapered beam (example in Fig. 8) and cantilever tapered beam. For each case, the load is applied uniformly on the upper flange. Furthermore, the uniform lateral support avoids any global lateral torsional buckling. Therefore, both failure modes (Vierendeel mechanism and webpost buckling) are expected to arise. The Fig. 9.a) presents an example of boundary conditions considered for the bi-supported tapered beam and the Fig. 9. (b) shows the corresponding failure mode due to web-post buckling.

In fire conditions, the model shows the failure mode of the web-post buckling for a bi-supported tapered beam (Fig. 9 (b)). The time of failure of the beam is represented by the acceleration of displacement on the displacement-time (or temperature) curve.

The ultimate load obtained from the numerical model is the maximum value in the nonlinear load-displacement curve. In fire conditions, the applied constant load is taken equal to $30 \%$ (usually the case for fire design) of the ultimate load given by the analytical model at normal temperature. The temperatures are applied uniformly and increased until the beam fails following the iso-fire curve given in Equation (18). The ultimate state is defined by the time of failure, corresponding to the critical temperature. The Fig. 10 shows the time-displacement curve at mid-span of a bi-supported tapered beam in fire condition and the out of plane displacement of two nodes located on both critical sections in the buckled web-post.

It can be observed that the time of failure corresponds to the web-post buckling of the cellular beam (Fig. 10). The initial part of the time-vertical displacement curve (until 20s) corresponds to the application of the mechanical load under normal temperature. When the mechanical load of $30 \%$ (of the analytical ultimate load) is reached, the heating starts and the curves show the evolution of the vertical and lateral displacements versus time (or temperature).

The comparisons of ultimate loads between the finite element model and the analytical model are presented in the next section for each beam configuration. In normal conditions, the failure loads given by the analytical model are compared to those ob- tained from the numerical model. In fire condition, the comparisons are made considering the critical temperatures.

\section{Validation of the analytical model for tapered and curved beams}

The validation of the analytical model, based on the finite element model, is done for tapered and curved beams considering normal and fire conditions. Firstly, cellular beams are analyzed in normal conditions considering bi-supported curved beam, bi-supported tapered beam and cantilever tapered beam. To cover realistic cases, various geometrical configurations are considered in the evaluation of the accuracy of the analytical model. Thus, for each geometrical parameter, three values are considered: two extreme values representing the maximum and the minimum, limited by construction practice [22], and a third value corresponding to the mean value. Secondly, the same configurations of beams are studied in fire conditions.

For all types of beams, it has been decided to vary:

- the web-post width $\mathrm{w}$, defined by the ratio $w / a_{0}\left(a_{0}\right.$ : opening diameter, see Fig. 1)

- the elastic limit $\left(f_{y}\right)$

- the parent profile (IPE, HEB or HEM)

Furthermore, for curved beams, it has been decided to vary the curvature radius $\mathrm{R}$, in order to study the influence of the curvature on the accuracy of the analytical model. Then, for the tapered beams, in addition to the three parameters, the ratio of the extreme heights $\left(H_{0} / H_{f}\right)$ is studied. This ratio allows studying the accuracy of the analytical model regarding the importance of height variation. In addition, the influence of keeping the same opening diameter along the tapered beam length is considered. Thus, for the bi-supported tapered beam, the opening diameter remains constant. Whereas for the cantilever beam, the opening diameter varies from $a_{00}$ to $a_{0 f}$ (with $a_{00}>a_{0 f}$, see Fig. 15). For all the parametrical study, the differences between the analytical and the numerical models are calculated through the ratio:

$$
\text { difference } \%=\frac{\text { FEM Value }- \text { Analytical Value }}{\text { FEM Value }} \times 100
$$

A positive value of this ratio means a conservative result of the analytical method in comparison with FEM.

\subsection{Curved and tapered beams in normal conditions}

In normal condition, the ultimate load given by the analytical model is compared to that of the finite element model. A parametrical study is led to observe the evolution of the difference between the models.

\subsubsection{Bi-supported curved beam}

The Fig. 11 shows an example of a bi-supported curved beam. The Fig. 12 shows the differences of ultimate loads between the finite element and the analytical models. 


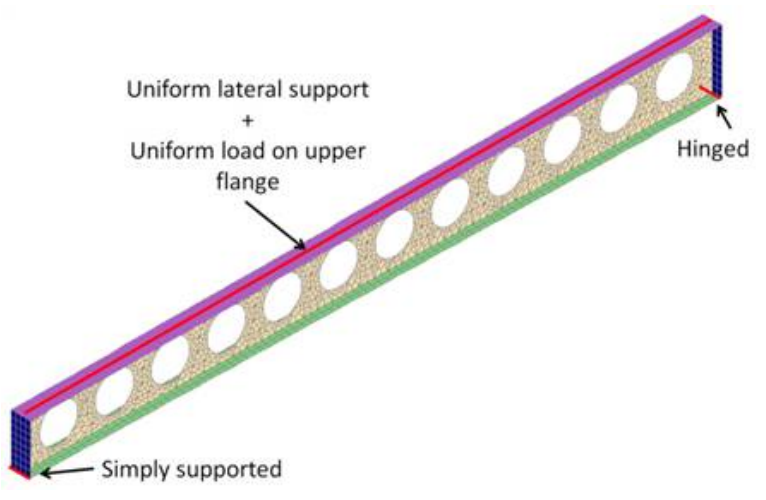

a) Example of boundary conditions

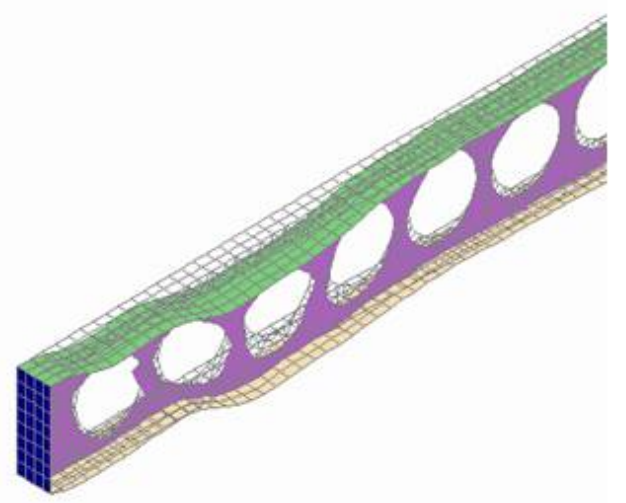

b) Web-post buckling failure mode

Fig. 9. Boundary conditions (a) and failure mode (b) for the FEM
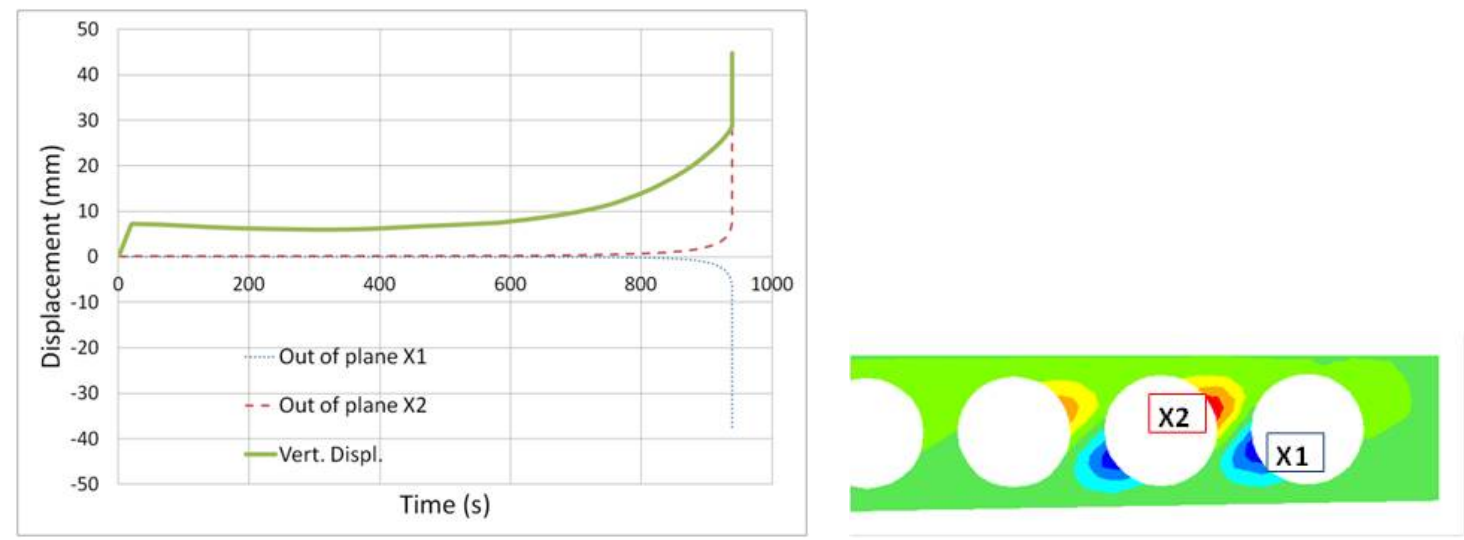

Fig. 10. Vertical displacement (mid-span) and out of plane displacements in the buckled web-post (points X1 and X2)

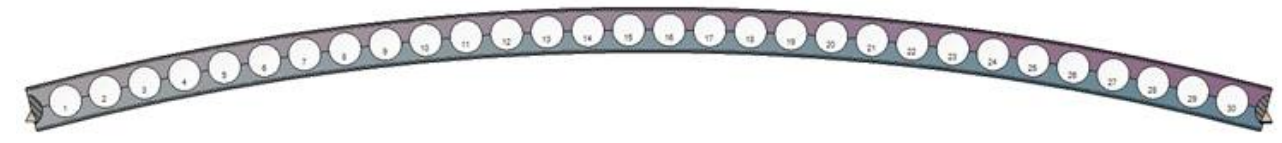

Fig. 11. Bi-supported curved beam 


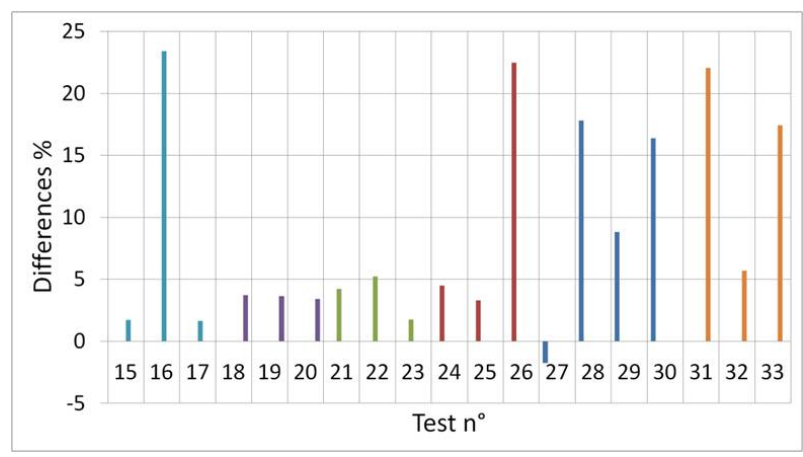

Fig. 12. Differences between the numerical and the analytical resistances for curved beams

The Table 1 summarizes the geometrical parameters and the failure modes of the studied configurations for both normal and fire conditions. The configurations that were tested only in normal conditions but not in fire appear in black boxes in the last column of the Table 1. For each test, the varied parameter is highlighted. It can be seen that for the Vierendeel yielding, the analytical model predicts the ultimate loads with a difference lower than $5 \%$ in comparison with the numerical model. However, with the WPB (web-post buckling) failure modes, it appears that the differences are higher $(\approx 20 \%)$.

It can be seen on Table 1 that the web-post buckling appears for narrow web-post with low ratio w/a $\mathrm{a}_{0}$. As the analytical model considers a straight " $\mathrm{X}$ " modulus, to calculate the compressive stresses in the web-post (see $\$ 2.4$ ), the influence of the curvature radius $(\mathrm{R})$ is observed.

The Fig. 13 shows the differences obtained for three values of curvature radius of curved beams. By varying the slenderness of the web-post (ratio $w / a_{0}$ ), the Fig. 13 points out that the differences remain the same for the studied curvature radius, but vary according to the ratio $w / a_{0}$ which influences the failure mode.

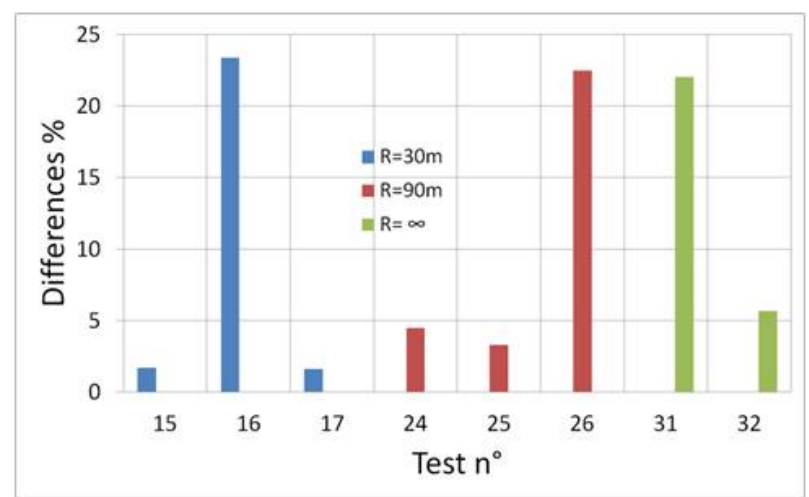

Fig. 13. Influence of the web-post width on the beams resistances with different curvature radius $(\mathrm{R}=30 \mathrm{~m}, 90 \mathrm{~m}$ and straight beam)

It can be seen on Fig. 13 that the application of the analytical model to curved beams gives satisfactory results regarding the ultimate failure load in comparison with the straight beams. Besides, the analytical model shows accurate results for curved beams for both failure modes. However, the less accurate results are obtained for the cases with extreme values of web-post width (around 50mm) which correspond to very narrow web-posts. In all cases, the analytical results are in the safe side for design practice.

\subsubsection{Bi-supported tapered beam}

The Fig. 14 shows the bi-supported tapered beam with a constant value of the opening diameter.

The Fig. 15 shows the differences between the analytical and the FEM models for bi-supported tapered beams. The analyzed configurations are shown in Table 2 and the varied parameters are highlighted. The configurations not tested in fire appear as black boxes in Table 2 .

It can be seen on Table 2 that the failure modes of all tested configurations concern the web-post buckling around the opening with the minimum height.

The results show that the accuracy of the analytical model decreases with the increase of the ratio $H_{0} / H_{f}$ (test $n^{\circ} 7,9$ ) and with the use of important profiles like HEB or HEM profiles (tests $n^{\circ} 12$ and 14). Furthermore, the accuracy increases with the increase of the web-post width. In all cases, the analytical model is conservative with a maximum difference with the finite element model of $20 \%$. However, the analytical model is more accurate for Vierendeel yielding failure mode in comparison with the web-post buckling failure mode.

\subsubsection{Cantilever tapered beam}

In the case of the cantilever beam, the opening diameter is varied according to the beam height. Therefore, the web-post width varies together with the opening diameter as the eccentricity between two openings remains constant. Thus, the intermediate web-post is rather slender at the first openings. As a consequence, it is frequently proposed to fill the first hole as illustrated on Fig. 16. The Fig. 16 shows the geometry studied with various parameters.

The Table 3 summarizes the different values of the studied geometrical parameters where the varied parameter is highlighted. The configurations not tested in fire conditions appear as black boxes in the Table. The Fig. 17 shows the differences obtained for the analyzed configurations.

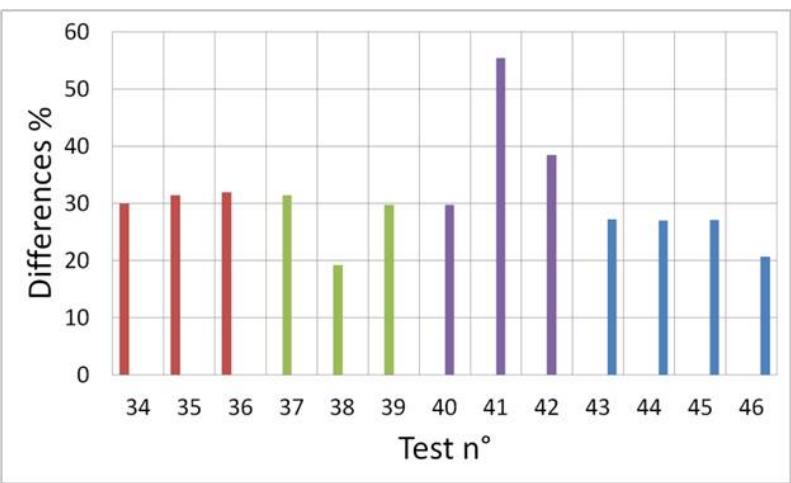

Fig. 17. Differences (\%) of ultimate loads between analytical and FEM results for the cantilever tapered beam

The web-post buckling appears to be the major failure mode in this configuration of cantilever tapered beam. It can be clearly 
Tab. 1. Configurations of bi-supported curved cellular beams and failure modes

\begin{tabular}{|c|c|c|c|c|c|c|c|c|c|}
\hline \multirow[t]{2}{*}{ Test $n^{\circ}$} & \multirow[t]{2}{*}{ Parent profil } & \multirow{2}{*}{$\begin{array}{c}\text { Elastic limit } \\
(\mathrm{MPa})\end{array}$} & \multirow[t]{2}{*}{$a_{0}(\mathrm{~mm})$} & \multirow[t]{2}{*}{$e(\mathrm{~mm})$} & \multirow[t]{2}{*}{$w / a_{0}$} & \multirow{2}{*}{$H_{t o t}(\mathrm{~mm})$} & \multirow[t]{2}{*}{$R(\mathrm{~m})$} & \multicolumn{2}{|c|}{ Failure mode FEM } \\
\hline & & & & & & & & $\begin{array}{c}\text { Normal } \\
\text { conditions }\end{array}$ & $\begin{array}{c}\text { Fire } \\
\text { conditions }\end{array}$ \\
\hline 15 & IPE 450 & 460 & 400 & 500 & 0.25 & 550 & 30 & $\begin{array}{c}\text { Vierendeel } \\
\text { yielding }\end{array}$ & WPB \\
\hline 16 & IPE 450 & 460 & 400 & 460 & 0.15 & 550 & 30 & WPB & WPB \\
\hline 17 & IPE 450 & 460 & 400 & 600 & 0.5 & 550 & 30 & $\begin{array}{c}\text { Vierendeel } \\
\text { yielding }\end{array}$ & WPB \\
\hline 18 & IPE 450 & 460 & 400 & 500 & 0.25 & 550 & 60 & $\begin{array}{c}\text { Vierendeel } \\
\text { yielding }\end{array}$ & \\
\hline 19 & IPE 450 & 355 & 400 & 500 & 0.25 & 550 & 60 & $\begin{array}{c}\text { Vierendeel } \\
\text { yielding }\end{array}$ & \\
\hline 20 & IPE 450 & 275 & 400 & 500 & 0.25 & 550 & 60 & $\begin{array}{c}\text { Vierendeel } \\
\text { yielding }\end{array}$ & \\
\hline 21 & IPE 450 & 460 & 400 & 500 & 0.25 & 550 & 60 & $\begin{array}{c}\text { Vierendeel } \\
\text { yielding }\end{array}$ & WPB \\
\hline 22 & IPE 450 & 460 & 400 & 500 & 0.25 & 550 & 90 & $\begin{array}{c}\text { Vierendeel } \\
\text { yielding }\end{array}$ & WPB \\
\hline 23 & IPE 450 & 460 & 400 & 500 & 0.25 & 550 & 30 & $\begin{array}{c}\text { Vierendeel } \\
\text { yielding }\end{array}$ & WPB \\
\hline 24 & IPE 450 & 460 & 400 & 500 & 0.25 & 550 & 90 & $\begin{array}{c}\text { Vierendeel } \\
\text { yielding }\end{array}$ & WPB \\
\hline 25 & IPE 450 & 460 & 400 & 600 & 0.5 & 550 & 90 & $\begin{array}{c}\text { Vierendeel } \\
\text { yielding }\end{array}$ & WPB \\
\hline 26 & IPE 450 & 460 & 400 & 450 & 0.125 & 550 & 90 & WPB & WPB \\
\hline 27 & IPE 270 & 460 & 250 & 312,5 & 0.25 & 370 & 90 & $\begin{array}{c}\text { Vierendeel } \\
\text { yielding }\end{array}$ & $\begin{array}{c}\text { Vierendeel } \\
\text { yielding }\end{array}$ \\
\hline 28 & HEB 280 & 460 & 250 & 312,5 & 0.25 & 370 & 90 & WPB & WPB \\
\hline 29 & IPE A450 & 460 & 400 & 500 & 0.25 & 550 & 90 & WPB & WPB \\
\hline 30 & HEM 280 & 460 & 235 & 293,75 & 0.25 & 370 & 90 & WPB & WPB \\
\hline 31 & IPE 450 & 460 & 400 & 500 & 0.125 & 550 & $\infty$ & WPB & \\
\hline 32 & IPE 450 & 460 & 400 & 500 & 0.25 & 550 & $\infty$ & $\begin{array}{c}\text { Vierendeel } \\
\text { yielding }\end{array}$ & \\
\hline 33 & HEB 280 & 460 & 250 & 312.5 & 0.25 & 370 & $\infty$ & WPB & \\
\hline
\end{tabular}

Tab. 2. Geometrical characteristics for the bi-supported tapered beam

\begin{tabular}{|c|c|c|c|c|c|c|c|c|c|c|}
\hline \multirow[t]{2}{*}{ Test $n^{\circ}$} & \multirow[t]{2}{*}{ Parent profil } & \multirow{2}{*}{$\begin{array}{l}\text { Elastic limit } \\
\quad(\mathrm{MPa})\end{array}$} & \multirow[t]{2}{*}{$a_{0}(\mathrm{~mm})$} & \multirow[t]{2}{*}{$e(\mathrm{~mm})$} & \multirow[t]{2}{*}{$w / a_{0}$} & \multirow[t]{2}{*}{$H_{0}(\mathrm{~mm})$} & \multirow[t]{2}{*}{$H_{f}(\mathrm{~mm})$} & \multirow[t]{2}{*}{$H_{0} / H_{f}$} & \multicolumn{2}{|c|}{ Failure mode FEM } \\
\hline & & & & & & & & & $\begin{array}{c}\text { Normal } \\
\text { conditions }\end{array}$ & $\begin{array}{c}\text { Fire } \\
\text { conditions }\end{array}$ \\
\hline 1 & IPE 600 & 355 & 450 & 540 & 0.2 & 750 & 600 & 1.25 & WPB & WPB \\
\hline 2 & IPE 600 & 355 & 450 & 648 & 0.44 & 750 & 600 & 1.25 & WPB & WPB \\
\hline 3 & IPE 600 & 355 & 450 & 580.5 & 0.29 & 750 & 600 & 1.25 & WPB & WPB \\
\hline 4 & IPE 600 & 355 & 450 & 580.5 & 0.29 & 750 & 600 & 1.25 & WPB & \\
\hline 5 & IPE 600 & 460 & 450 & 580.5 & 0.29 & 750 & 600 & 1.25 & WPB & \\
\hline 6 & IPE 600 & 235 & 450 & 580.5 & 0.29 & 750 & 600 & 1.25 & WPB & \\
\hline 7 & IPE 600 & 355 & 350 & 450 & 0.29 & 900 & 500 & 1.8 & WPB & WPB \\
\hline 8 & IPE 600 & 355 & 500 & 650 & 0.3 & 900 & 700 & 1.29 & WPB & WPB \\
\hline 9 & IPE 600 & 355 & 250 & 350 & 0.4 & 900 & 350 & 2.57 & WPB & WPB \\
\hline 10 & IPE 600 & 355 & 600 & 800 & 0.33 & 825 & 825 & 1 & WPB & \\
\hline 11 & IPE 300 & 355 & 250 & 312.5 & 0.25 & 424.3 & 349.7 & 1.21 & WPB & WPB \\
\hline 12 & HEB 300 & 355 & 250 & 312.5 & 0.25 & 404 & 341.6 & 1.18 & WPB & WPB \\
\hline 13 & IPEA 600 & 355 & 450 & 580.5 & 0.29 & 750 & 600 & 1.25 & WPB & WPB \\
\hline 14 & HEM 300 & 355 & 250 & 312.5 & 0.25 & 444 & 381.6 & 1.16 & WPB & WPB \\
\hline
\end{tabular}




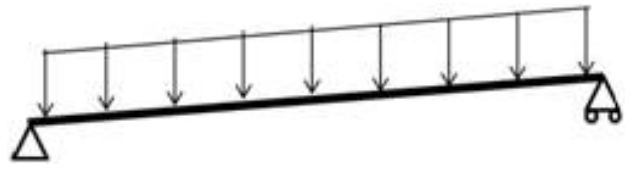

Fig. 14. Bi-supported tapered cellular beam with constant opening diameter

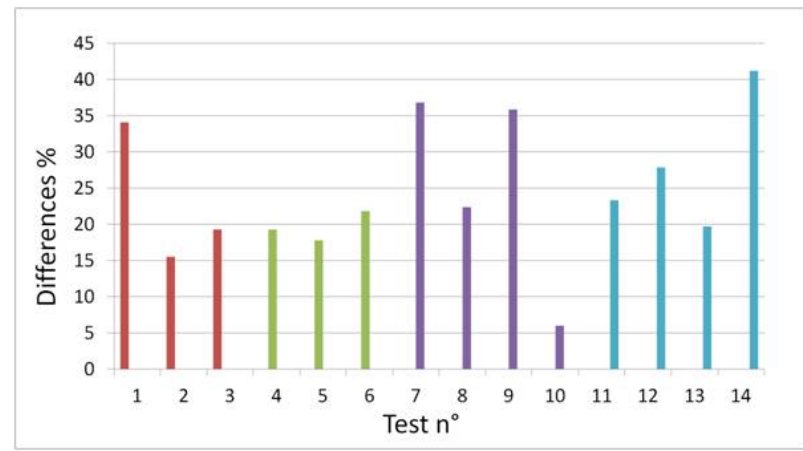

Fig. 15. Comparison of analytical and FEM results for the simply supported cellular beam
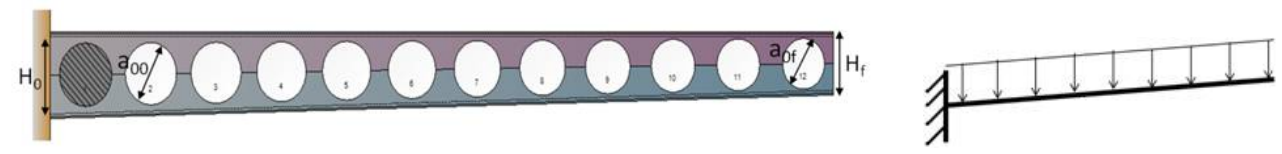

Fig. 16. Cantilever tapered beam with varying opening diameters

Tab. 3. Geometrical characteristics for the cantilever tapered beam and failure modes

\begin{tabular}{|c|c|c|c|c|c|c|c|c|c|c|c|}
\hline \multirow[t]{2}{*}{ Test $\mathrm{n}^{\circ}$} & \multirow{2}{*}{$\begin{array}{l}\text { Parent } \\
\text { profil }\end{array}$} & \multirow{2}{*}{$\begin{array}{c}\text { Elastic } \\
\text { limit (MPa) }\end{array}$} & \multirow[t]{2}{*}{$a_{00}(\mathrm{~mm})$} & \multirow[t]{2}{*}{$a_{0 f}(\mathrm{~mm})$} & \multirow[t]{2}{*}{$e(\mathrm{~mm})$} & \multirow[t]{2}{*}{$w / a_{0}$} & \multirow[t]{2}{*}{$H_{0}(\mathrm{~mm})$} & \multirow[t]{2}{*}{$H_{f}(\mathrm{~mm})$} & \multirow[t]{2}{*}{$H_{0} / H_{f}$} & \multicolumn{2}{|c|}{ Failure mode FEM } \\
\hline & & & & & & & & & & $\begin{array}{c}\text { Normal } \\
\text { conditions }\end{array}$ & $\begin{array}{c}\text { Fire } \\
\text { conditions }\end{array}$ \\
\hline 34 & IPE 360 & 275 & 400 & 265 & 450 & 0.17 & 550 & 400 & 1.375 & WPB & WPB \\
\hline 35 & IPE 360 & 275 & 400 & 320 & 500 & 0.28 & 550 & 400 & 1.375 & WPB & WPB \\
\hline 36 & IPE 360 & 275 & 400 & 320 & 550 & 0.41 & 550 & 400 & 1.375 & $\begin{array}{c}\text { Vierendeel } \\
\text { yielding }\end{array}$ & WPB \\
\hline 37 & IPE 360 & 275 & 400 & 320 & 500 & 0.28 & 550 & 400 & 1.375 & $\begin{array}{c}\text { Vierendeel } \\
\text { yielding }\end{array}$ & \\
\hline 38 & IPE 360 & 460 & 400 & 320 & 500 & 0.28 & 550 & 400 & 1.375 & WPB & \\
\hline 39 & IPE 360 & 355 & 400 & 320 & 500 & 0.29 & 550 & 400 & 1.375 & WPB & \\
\hline 40 & IPE 360 & 355 & 400 & 320 & 500 & 0.29 & 550 & 400 & 1.375 & WPB & WPB \\
\hline 41 & IPE 600 & 355 & 500 & 330 & 553,5 & 0.17 & 1000 & 420 & 2.38 & WPB & WPB \\
\hline 42 & IPE 600 & 355 & 490 & 380 & 580 & 0.23 & 950 & 600 & 1.58 & WPB & WPB \\
\hline 43 & IPE 600 & 355 & 475 & 365.8 & 560 & 0.23 & 800 & 670 & 1.19 & WPB & WPB \\
\hline 44 & HEB 360 & 355 & 400 & 320 & 500 & 0.29 & 550 & 440 & 1.375 & WPB & WPB \\
\hline 45 & IPEA 600 & 355 & 475 & 365,8 & 560 & 0.29 & 800 & 670 & 1.19 & WPB & WPB \\
\hline 46 & HEM 360 & 355 & 386.2 & 285.7 & 498.2 & 0.34 & 550 & 440 & 1.375 & WPB & WPB \\
\hline
\end{tabular}


seen that the accuracy of the analytical model depends mostly on the ratio of the extreme heights, $H_{0} / H_{f}$, which reveals the importance of the neutral fiber slope (tests $n^{\circ} 41$ and 42 ). The analytical model seems less accurate for beams with the highest values of ratio $H_{0} / H_{f}$.

It can be observed that the analytical model remain always conservative in comparison with the FEM model. The analytical model does not consider the axial force due to the neutral axis slope in the calculation of the horizontal shear force which creates the web-post buckling. In the case of cantilever beams, this axial force increases for sections close to the clamping and this axial force is opposed to the horizontal shear force which should reduce its impact on the web-post buckling. However this analytical model gives acceptable results, and the important differences obtained are usually for cases with extreme values of web-post width or ratio $H_{0} / H_{f}$. Therefore, for standard configurations of cantilever tapered cellular beams, the analytical model can be considered validated in comparison with the finite element model results.

The approach developed in normal conditions is applied in fire conditions. However, as the applied load in fire remains constant, the comparisons are performed considering the critical temperature.

\subsection{Curved and tapered beams in fire conditions}

For a specified load, the critical temperature of the web-post buckling is calculated using the analytical model presented here above. This temperature is compared with that given by the FEM model. In order to validate the analytical model extended to curved or tapered beam, the configurations, analyzed in normal conditions, are modeled considering the evolution of temperature and as a consequence the changes in the mechanical characteristics of steel (see Tables 1, 2 and 3). In fire conditions, the stiffness of steel decreases faster than the elastic limit. Thus, buckling phenomenon are predominant compared to yielding. As a consequence, the web-post buckling is more expected to arise with elevated temperatures, the tables 1 to 3 give the corresponding failure mode at elevated temperatures for each studied beam.

\subsubsection{Bi-supported curved beams}

The finite element model shows that, as expected in fire conditions, the web-post buckling is the main failure mode due to the loss of stiffness influenced by the elevated temperature. The Fig. 18 shows the differences between the FEM and the analytical results.

It can be observed that the analytical results remain conservative for all the tests except for the $n^{\circ} 27$. The test $n^{\circ} 27$ corresponds to the case with the formation of a local hinge by Vierendeel mechanism. The difference obtained $(2 \%)$ show that in the case of plastic failure, the analytical model is much more accurate. The differences between the finite element model and the analytical model are less than $7 \%$, which show that the analyti-

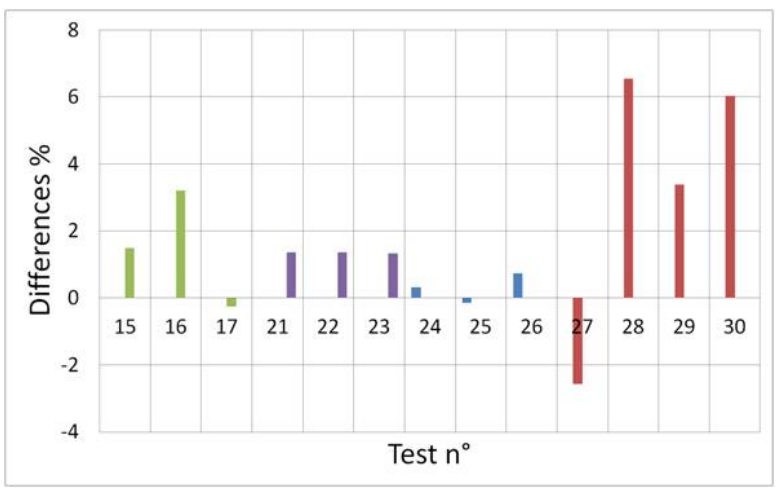

Fig. 18. Differences of critical temperature between FEM and analytical models for curved beams in fire

cal model predicts well the critical temperature even at its limits of validity. For example, with a curvature radius of $30 \mathrm{~m}$ near the limits of validity of the analytical model, a good approximation of the critical temperature is obtained.

\subsubsection{Bi-supported and cantilever tapered beams}

As for the previous comparative study at normal conditions, both configurations of tapered beams, bi-supported beams (test $n^{\circ} 1-14$ ) and cantilever beams (tests $n^{\circ} 34-46$ ), are considered (see Fig. 19.

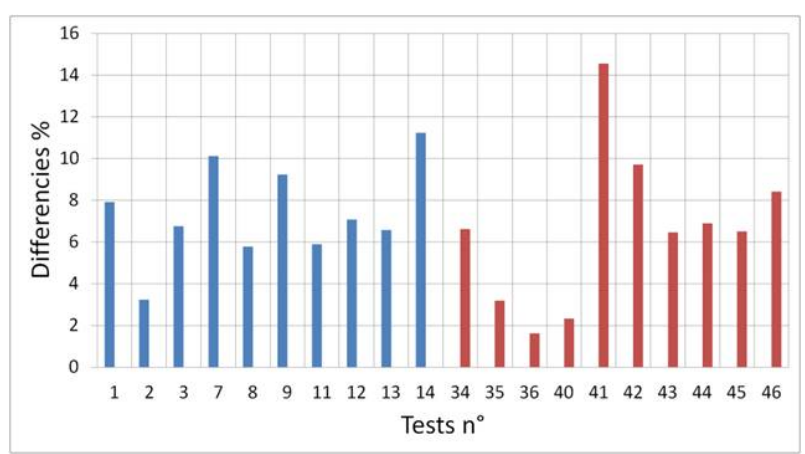

Fig. 19. Comparison of numerical and analytical results for the tapered beams in fire

In all the studied cases, the analytical model is conservative in comparison with the FEM model (Fig. 19). It can be observed that the accuracy of the analytical model increases with the increase of the web-post width $\left(n^{\circ} 1,2,3\right.$ and $\left.34,35,36\right)$. Furthermore, the tests $n^{\circ} 7,8,9,40,41$ and 42 show the influence of the height's variation ratio $\left(H_{0} / H_{f}\right)$. It can be observed that the model accuracy decreases with the increase of this ratio. Generally the same comment can be made in fire or normal conditions. The major differences are obtained for narrow web-posts $\left(w / a_{0}<0.2\right)$ and tapered beams with an important variation of heights. Furthermore, it can be noted that the accuracy of the analytical model can be influenced by the type of section. The models seems to be better adapted to slender profiles like IPE than for more massive profiles such as HEB or HEM (tests $n^{\circ} 12$, 14, 44 and 46).

In all cases, the average value of the differences between the analytical model and the finite element model is lower than that 
of normal conditions $(<10 \%)$. The analytical method for fire conditions can be considered as validated on the basis of finite element results.

The values of failure resistance are summarized in Table 4 for all the studied cases in fire and normal conditions.

Tab. 4. Summary of the differences between FEM and analytical results for the studied configurations

\begin{tabular}{|c|c|c|c|}
\hline \multicolumn{2}{|c|}{ Configuration } & $\begin{array}{l}\text { Average of the } \\
\text { differences \% }\end{array}$ & $\begin{array}{c}\text { Maximum } \\
\text { difference \% }\end{array}$ \\
\hline \multirow{3}{*}{ Normal condition } & $\begin{array}{l}\text { bi-supported } \\
\text { curved beam }\end{array}$ & 9.18 & 23 \\
\hline & $\begin{array}{l}\text { bi-supported } \\
\text { tapered beam }\end{array}$ & 24.3 & 41 \\
\hline & $\begin{array}{c}\text { cantilever } \\
\text { tapered beam }\end{array}$ & 30.7 & 55 \\
\hline \multirow{3}{*}{ Fire condition } & $\begin{array}{l}\text { bi-supported } \\
\text { curved beam }\end{array}$ & 1.75 & 6.5 \\
\hline & $\begin{array}{c}\text { bi-supported } \\
\text { tapered beam }\end{array}$ & 7.38 & 11 \\
\hline & $\begin{array}{c}\text { cantilever } \\
\text { tapered beam }\end{array}$ & 6.62 & 14 \\
\hline
\end{tabular}

\section{Conclusions}

The existing analytical model for straight cellular beams is extended to curved and tapered beams at normal and fire conditions. A finite element model is developed using shell elements and considering the nonlinear behavior of material and large displacement. The accuracy of the analytical model is evaluated by comparison with the finite element results. The comparisons are performed on three configurations of beams: bi-supported curved beam, bi-supported and cantilever tapered beams.

The comparative study pointed out many results. First, the accuracy of the analytical model decreases when the failure mode is web-post buckling in comparison with the Vierendeel plastic mode. The adaptation of the analytical model to curved beams shows that the differences are around 5\% for the Vierendeel yielding mode and around $20 \%$ with web-post buckling failure mode. Besides, it is observed that the main influent parameter on the accuracy of the model is the web-post width, which influences the failure mode (web-post buckling or not). The variation of the curvature radius does not influence the accuracy of the analytical model.

In tapered beams, the analytical model is less accurate for the web-post buckling. The differences reached 20 to $30 \%$. The accuracy decreases with the decrease of the web-post width and the increase of the extreme height ratio $\left(H_{0} / H_{f}\right)$. However, in all cases, the analytical model gives conservative results for the ultimate failure load with the maximum differences for extreme geometrical parameters values. Therefore, the analytical model can be considered validated and can be used for pre-design or design purpose.

The adaptation of the analytical model to elevated temperatures shows a good accuracy in comparison with the finite el- ement model. In fire conditions, the web-post buckling is the predominant failure mode. As in normal conditions, the main parameter influencing the accuracy of the analytical model is, for tapered or curved beams, the web-post width. Extremely slender web-posts $\left(w / a_{0}<0.2\right)$ lead to maximum differences. Furthermore, larger differences are observed for tapered beams with high slopes or cellular beams designed from heavy profiles. However, in all cases, the mean value of the differences remain conservative and close to the numerical model $(<10 \%)$ which permits to consider the analytical approach, for tapered or curved beams in fire conditions, validated.

In all cases, the analytical model is conservative in comparison with the finite element model. Thus, it can be used in design practice. However improvements in the web-post buckling model is to be performed in a larger database of profiles mainly for tapered beams.

\section{References}

1 Sweedan AMI, Elastic lateral stability of I-shaped cellular steel beams, Journal of Constructional Steel Research, 67, (2011), 151-163, DOI 10.1016/j.jcsr.2010.08.009.

2 Kerdal D, Nethercot DA, Failure modes of castellated beams, Journal of Constructional Steel Research, 4, (1984), 295-315, DOI 10.1016/0143974X(84)90004-X.

3 Chung KF, Lawson RM, Simplified design of composite beams with large web openings to Eurocode 4, Journal of Constructional Steel Research, 57, (2001), 135-164, DOI 10.1016/S0143-974X(00)00011-0.

4 Lawson RM, Lim J, Hicks SJ, Simms WI, Design of composite asymmetric cellular beams and beams with large web openings, Journal of Constructional Steel Research, 62, (2006), 614-629, DOI 10.1016/j.jcsr.2005.09.012.

5 Ferhat E, Erkan D, Mehmet PS, Optimum design of cellular beams using harmony search and particle swarm optimizers, Journal of Constructional Steel Research, 67, (2011), 237-247, DOI 10.1016/j.jcsr.2010.07.014.

6 Bitar D, Poutre en I à âme élancée-vérification de la résistance d'un panneau d'âme muni d'une ouverture circulaire centrée, Revue Construction Métallique, 4, (2004), 71-91.

7 ENV 1993-1-1, Eurocode 3. Design of steel structures - Part 1-1: General rules and rules for buildings, Annexe N, CEN, 1995.

8 Large web Openings for service integration in composite floor, ECCS, 2006. ECSC contract 7210- PR-315.

9 Ward JK, Design of Composite and Non-Composite Cellular Beams, SCI Publication, 1990. 100.

10 Darwin D, Design of Steel and Composite Beams with Web Openings, Design Guide 2, AISC, 2003. third edition, 65 pages.

11 Bitar D, Martin PO, Galéa Y, Demarco T, Poutres cellulaires acier et mixtes : Partie 1, proposition d'un modèle pour la résistance des montants, Revue Construction Métallique, 1, (2006), 15-39.

12 Wong VB, Burgess I, Plank R, Behaviour of composite cellular steelconcrete beams at elevated temperatures, International journal of steel structures, 9, (2009), 29-37.

13 Vassart O, Analytical model for cellular beams made of hot rolled sections in case of fire, PhD thesis, Université Blaise Pascal, 2009.

14 Majoros É, Balázs GL, Degree of deterioration due to fire in large concrete halls, Periodica Polytechnica - Civil Engineering, 48(1-2), (2004), 141-156, DOI 10.3311/pp.ci.2004-1-2.12.

15 Bailey C, Indicative fire tests to investigate the behavior of cellular beams protected with intumescent coatings, Fire Safety Journal, 39, (2004), 689709, DOI 10.1016/j.firesaf.2004.06.007. 
16 Nadjai A, Vassart O, Ali F, Talamona D, Allam A, Hawes M, Performance of cellular composite floor beams at elevated temperatures, Fire Safety Journal, 42, (2007), 489-497, DOI 10.1016/j.firesaf.2007.05.001.

17 Naili E, Nadjai A, Song H, Ali F, Choi S, Wong B, Burges I, Plank R, Experimental and Numerical Modelling of Cellular Beams with Elongations Openings at Elevated Temperature, Structures in fire - 6th international conference (SiF' 10), (Michigan State University, 2010), In: Kodur V, Franssen JM (eds.), Structures in Fire, DEStech Publications, Inc, 2010, pp. 98-105.

18 Vassart O, Bailey CG, Hawes M, Nadjai A, Simms WI, Zhao B, Gernay T, Franssen JM, Large-Scale Fire test of Unprotected Cellular Beam Acting in Membrane Action, Journal of Structural Fire Engineering, 2(4), (2011), 259-267, DOI 10.1260/2040-2317.2.4.259.

19 Durif S, Bouchaïr A, Vassart O, Experimental tests and numerical modeling of cellular beams with sinusoidal openings, Journal of Constructional Steel Research, 82, (2013), 72-87, DOI 10.1016/j.jcsr.2012.12.010.

20 Tsavdaridis KD, Structural performance of perforated steel beams with novel web openings and with partial concrete encasement, $\mathrm{PhD}$ thesis, School of Engineering and Mathematical Sciences, City University, London, 2010.

21 EN1993-1-2, Eurocode 3: Design of steel structures - Part 1-2: General rules - Structural fire design, CEN, 2003.

22 Mangin P, Bureau A, ArcelorMittal Cellular Beam Software ACB+: technical descriptive, Centre Technique Industriel de la Construction Métallique CTICM, 2009. report No. 7,072-01.

23 Durif S, Vassart O, Bouchaïr A, Muzeau JP, Analytical model for cellular beams in normal and fire conditions, 6th European Conference on Steel and Composite Structures, Eurosteel 2011, (Budapest, 2011-08-31), In: Dunai L, Ivanyi M, Jarmai K, Kovács N, Vigh L G (eds.), Eurosteel 2011, ECCS Press, 2011, pp. 1623-1628. Vol. B.

24 EN1991-1-2, Eurocode 1: Actions on structures - Part 1-2: General actions - Actions on structures exposed to fire, CEN, 2003.

25 Jakab G, Dunai L, Laboratory and virtual experiments on C-section compression members with semi-rigid connections, Periodica Polytechnica Civil Engineering, 54(1), (2010), 31-43, DOI 10.3311/pp.ci.2010-1.04.

26 Liu TCH, Chung KF, Steel beams with large web openings of various shapes and sizes: finite element investigation, Journal of Constructional Steel Research, 59, (2003), 1159-1176, DOI 10.1016/S0143-974X(03)00030-0.

27 Ellobody E, Nonlinear analysis of cellular steel beams under combined buckling modes, Thin Walled Structures, 52, (2012), 66-79, DOI 10.1016/j.tws.2011.12.009.

28 Soltani MR, Bouchaïr A, Mimoune M, Nonlinear FE analysis of the ultimate behavior of steel castellated beams, Journal of Constructional Steel Research, 70, (2012), 101-114, DOI 10.1016/j.jcsr.2011.10.016. 